\title{
A New Mindset for Circular Economy Strategies: Case Studies of Circularity in the Use of Water
}

\author{
Elisabeth Viles ${ }^{1}{ }^{\mathbb{D}}$, Javier Santos ${ }^{1} \mathbb{D}$, Tamara Fernández Arévalo ${ }^{2}{ }^{\mathbb{D}}$, Martín Tanco $^{3}$ \\ and Florencia Kalemkerian ${ }^{3, *}$ \\ 1 TECNUN, Escuela de Ingenieros, Universidad de Navarra, 20018 San Sebastián, Spain; \\ eviles@tecnun.es (E.V.); jsantos@tecnun.es (J.S.) \\ 2 CEIT-Basque Research and Technology Alliance (BRTA), 20018 San Sebastian, Spain; tfernandez@ceit.es \\ 3 CINOI, Centro de Innovacion en Organizacion Industrial, Universidad de Montevideo, \\ Montevideo 11300, Uruguay; mtanco@um.edu.uy \\ * Correspondence: fkalemkerian@correo.um.edu.uy
}

Received: 16 October 2020; Accepted: 19 November 2020; Published: 23 November 2020

check for updates

\begin{abstract}
In a circular economy (CE) environment, it is important to make good and efficient use of resources and consider that the waste generated in production processes can be a valuable resource. However, the tools and methodologies conventionally used to analyze and evaluate production systems are based on techniques focused on linear production management models, where the primary purpose is to reduce the treatment and management of waste as much as possible and where productive and environmental efficiency are not evaluated simultaneously. Changing the paradigm from a linear to a circular economy requires that a new strategy for production systems be defined, one that makes production processes simultaneously circular and efficient (in terms of quality and productivity). In this context, a holistic vision is needed when implementing CE strategies. Therefore, the main aim of this paper is to provide evidence, through two real case studies in the use of water, that the management of this resource without considering systemic thinking may not be the most circular solution. Main results showed that improvements based on the traditional approach of reducing resource use cannot provide the best results if they are supported only by current process consumption without considering the circularity of resources.
\end{abstract}

Keywords: production system; circular economy; case study; UN SDG 17; water management; circularity thinking

\section{Introduction}

No one doubts any longer that organizations must contribute directly to a more sustainable world. For a few years now, it has been demonstrated that the linear economic (LE) model that has prevailed since the industrial revolution does not contribute to sustainability. Therefore, the circular economy (CE) is now irreversible. This new paradigm has been useful to understand how resources can be managed most efficiently [1].

The term "circular economy" was first coined in 1990 [2]. Since then, many definitions of CE have been given [3]. The ECoPYME project, led by TECNUN (DPI2015-70832-R (MINECO/FEDER)), defined circular economy to include different sensitivities: "an economic system that represents a change of paradigm in the way in which human society is interrelated with nature and seeks to avoid the depletion of resources, close energy and material ties and facilitate sustainable development through its implementation at the micro level (businesses and consumers), meso level (economic agents integrated in symbiosis) and macro level (cities, regions and governments)" [4]. Additionally, the nano level has 
been coined [5] for applying CE principles to processes or products. Figure 1 shows the different areas of implementation of CE.

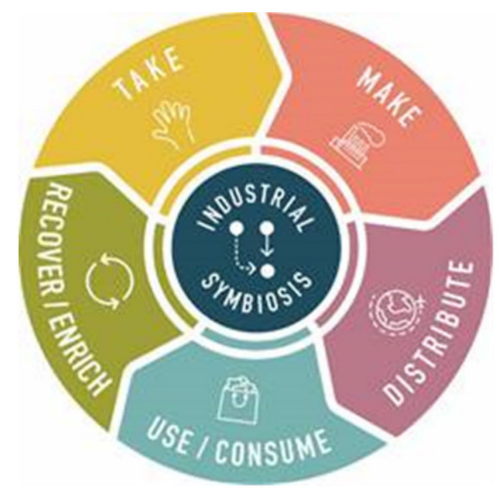

Figure 1. Action fields in the Circular Economy paradigm [6].

In this context, the Circular Economy supports three principles [7]:

- Preserving and enhancing natural capital by controlling finite reserves, balancing flows of renewable resources and providing utility whenever possible.

- Optimize the performance of resources by distributing products, components and materials, while seeking their maximum utility at all times.

- Promote the efficiency of systems by detecting and eliminating negative external factors from the design.

These principles involve designing to remanufacture, recondition and recycle, in order to keep technical components and materials circulating and thus contributing to optimizing the economy. Additionally, they include avoiding or at least reducing possible damage and adequately controlling other important external factors, such as land use, air and water pollution, or the release of toxic substances.

In December 2015, the European Commission presented the CE as a new economic model based on minimizing the environmental impact of products throughout their life cycle and that has the additional objective of boosting work, growth and investment to develop a competitive economy while being resource efficient and minimizing carbon dioxide emissions.

Since then, public and private bodies have carried out countless research studies and spearheaded initiatives to accelerate the transition from a linear economy to a circular economy at different social levels. From 2016 to 2020, the European Commission invested more than 10 billion euros in research, innovation and support. The recent European Green Deal places the concept of CE at the center of its efforts to achieve a cleaner and more competitive Europe, where industrial and systemic innovation is a crucial point in the transition towards a sustainable CE. European Union (EU) actions have also led member states to adopt strategies to make the transition from a linear to a circular economy.

At the micro and nano level, several authors have compiled a set of practices that any organization can use to embark on its transition path towards a CE model [2,8-13]. These practices are based on the optimization of the use of energy necessary for the manufacture of the product and for its sale, the use of sustainable design or eco-design strategies and the use of new materials that are less contaminating and more sustainable.

A review of recent literature on the strategies used in the deployment of CE reveals that manufacturing, distribution and sales are the areas in the entire $C E$ value chain which receive less attention in the literature, with manufacturing receiving the least attention. In the context of manufacturing, some of the strategies identified are circular design, material efficiency, cleaner production, disassembly and the 3Rs (reduce, reuse, recycle), servitization, industrial symbiosis or closed-loop supply chain [14]. For the optimization of water management in industrial processes, 
Europe is calling for implementing reuse and recycling strategies [15]. However, authors in [14] concluded that most of the studies in the existing literature report that each strategy gets implemented as a separate entity and little attention has been paid to how strategies can be adopted concurrently in a bid to encourage manufacturers to embrace the CE.

In this context, a literature review carried out by Schöggl et al., 2020 [16] mentioned that a holistic approach is needed while designing in a CE framework. Therefore, the CE has to be implemented outside organizations and in a more holistic way, through more collaboration with stakeholders on CE efforts and activities [17]. This idea of "holistic approach" ought to be applied at the nano level when trying to improve a production process; indeed, all the variables involved in the process should be considered rather than focusing the analysis on only one isolated variable.

In order to efficiently shift the classic management of companies towards the new economic paradigm, the development of specific CE indicators and integrated management models are needed $[18,19]$. However, only a few of the circular indicators attempt to provide a more holistic approach that considers both intrinsic circularity and its effects [20]. In line with this, Moraga et al. [21] mentioned that most indicators focus on the preservation of materials and those strategies which are focused on materials. Most of those indicators use the current state of the materials' value.

When applying a CE perspective, if waste from a process can become a resource (which is called a waste-resource) or it can be reused, it would be necessary to develop new production strategies to include this approach.

With regard to measuring the efficiency of the implementation of CE practices, the Polish scientific literature presents a waste consumption indicator for a production process, which contemplates both production productivity and thus indirectly its efficiency, as well as the impact of relevant processes on the environment [22]. However, this indicator is not popular in practice. Sanchez-Ortiz et al. [18] found that challenges include establishing indicators, the difficulty of defining the indicators and the impossibility of obtaining the data. To monitor all the resources used throughout the entire product life cycle, there is a need for data and information circulation $[16,20]$. This idea also ought to be considered when improving production process in the manufacturing area from the CE perspective. Digital technologies such as the Internet of Things (IoT), big data and data analytics are considered as essential enablers of the circular economy and can support companies in becoming more resource-efficient since they provide production systems with historical and real-time data [23].

Based on what has been observed in the literature, we formulated the following hypotheses:

Hypothesis 1 (H1). The traditional strategies for making improvement in manufacturing, which are focused on a linear production management, do not allow manufacturers to obtain the real benefits of CE.

Hypothesis 2 (H2). The conventional metrics and tools do not facilitate productive and environmental efficiency to be simultaneously evaluated in a CE context.

With the aim of testing the proposed hypotheses and by focusing on companies at the nano level, this paper presents two real case studies related to water management in manufacturing, specifically in the agri-food sector. The main purpose of the research is to compare the traditional management and improvement approach of this resource with an improvement approach based on the CE paradigm.

The structure of the paper is as follows. Section 2 presents the theoretical background of the circular economy in the production process. Section 3 presents the research methodology, followed by the results in Section 4. Finally, the main research conclusions are presented in Section 5.

\section{Theoretical Background}

One of the main objectives of the CE is that the natural resources consumed in production have an unlimited life through reusing the waste generated by the production process itself and reusing the products themselves once they become waste; achieving unlimited life could solve the 
growing demand for natural resources that are increasingly scarce [18]. In particular, water efficiency has become a key issue at the EU Action Plan for a circular economy [24]. Water is an important resource in the manufacturing industry and its efficient management is imperative for organizations due to increasingly strict environmental regulations, wastewater treatment costs and the shortage of freshwater resources [25]. In order to achieve the goals of sustainable development, implementing CE principles is increasingly recommended [20], since the CE paradigm is considered to be one of the major drivers for sustainability [14]. In this context, production operations are a necessity in order to address today's requirements on sustainability [26].

In the manufacturing area, the strategies most frequently promoted to help companies to start moving in the direction of the $\mathrm{CE}$ are designing processes to minimize waste generation, or to reduce process re-consumption $[12,13]$. In water intensive industries, a practice that is implemented with a growing tendency is the separation of sewage streams with different properties at the source, since it facilitates decentralized treatment and reuse [27]. In this line, for water management, Kurdve et al. [26] identified some circular initiatives such as recycling and reusing at the food production industry [28], and in the textile and tannery sector [29]. Additionally, by closing open loops of some manufacturing process in a food and beverage company, water efficiency was improved and water consumption was reduced by $45 \%$ [24]. Although these practices allow companies to meet most of the environmental objectives, they are not necessarily in line with the CE perspective; in order to transition to a CE, reduction strategies should embrace every aspect of production and consumption [30]. In this context, researchers claim that organizations are focused on reduction as part of the 3Rs (reduce, reuse, recycle) but do not so under the CE umbrella; instead organizations are in favor of reducing and recycling from an internal point of view [17]. Some efforts to support a circular manufacturing strategy have focused on a single strategy and some key variables and stakeholders are not considered [14]. A case study conducted by Bressanelli, et al. [31] in the household appliance industry concluded that the majority of the companies employ one single strategy of the $4 \mathrm{R}$ hierarchy (reduce, reuse, remanufacture, recycle) and do not implement them in a systemic and cascading way as the literature recommends.

Carrying out sustainable practices in the manufacturing area in accordance with the principles of the $\mathrm{CE}$ requires innovation in products and processes but also the optimization of existing ones [32]. Addressing disruptive changes in processes that favor sustainable and fair growth from the outset can sometimes be questionable in terms of the potential loss of competitiveness. The large investments required, the lack of maturity in the technologies, the possible disruptions in quality and/or productivity achieved years ago, etc. are other situations that may arise with a change in paradigm.

A review of the literature yields numerous publications that conclude that there is interest in providing industries with methodologies and tools that facilitate the adoption of efficient environmental management and production practices in a joint manner [33,34]. However, there is no evidence of the existence of general indicators that measures productive and environmental efficiency simultaneously. Such an indicator would not only advocate for the local reduction of waste-resources per se since the most widely used indicators are based not on CE in general [18] but on the 3R principles of waste (reduce, reuse, recover); it would also try to make a good and efficient use of resources throughout the manufacturing process and with circular aims. As an example, in the paper industry, the definition of indicators to assess circularity practices in wastewater treatment operations makes the decision-making process easier and allows the adoption of operational decisions towards more circular strategies $[35,36]$.

There are also several research papers that present taxonomies of circularity measurements $[5,20]$ and even different conceptual frameworks for measuring the circularity of systems at different levels [12]. A water circularity index (WCI) was proposed by Sartal et al., 2020 [24] to evaluate the level of circularity in the use of water, which contemplates the volume of virgin water, the wastewater that consists of polluted and discharged water and total volume of water used for plant operations. Several indexes were defined specifically for the wastewater treatment industry; authors in [37] presented an index to measure circularity production efficiency as well as recycling and reuse efficiencies. In this context, a circular economy efficiency indicator was proposed to provide information about the water recovered 
during pig manure treatment [36] and during a paper manufacturing process [35]. The implementation of those indicators showed a reduction in water consumption in wastewater treatments.

The concepts of LCA (life cycle assessment) and WF (water footprint) have been adopted in a generalized way to evaluate and improve the environmental impact in the production of goods and services [38]. WF consists of a multi-dimensional indicator that shows water consumption volumes by source and polluted volumes by the type of pollution. According to Skouteris et al. [25], the combined use of WF with pinch analysis can provide water intensive manufacturing industries with a powerful management tool that can improve their water consumption and their long term sustainability. Other methodologies based on LCA and other metrics-including Ecotax, Ecovalue08, Ecoindicator-99 and Ecoinvent 3-have been widely used to calculate the environmental impact in production processes, etc. However, the reduction in environmental costs is not sufficient for companies if it is not accompanied by greater efficiency and economic profitability.

Monitoring, measurement and analysis play an important role in efficiency and economic profitability, but they lose their usefulness and meaning if measurements are taken independently of the complete production process and in isolation from a company context [39]. After an analysis of the new measurements proposed at the micro level, it can beconcluded that there are measures related to the evaluation of the $\mathrm{CE}$ that include economic terms, but none of these measures of circularity allow organizations to estimate, even partially, the economic consequences they will experience when adopting CE principles. The environmental indicators currently used are not useful tools for improving productivity. Companies need to measure the efficiency of the waste recovery strategies that they have implemented through the feedback provided by reliable indicators adapted to the CE context, which should help companies to make decisions that are focused not so much on immediate profitability as on stable and sustained growth [18].

In summary, our review of the literature makes it clear that the new CE paradigm implies a new approach when implementing continuous improvement actions that seek improvements in the production area (productivity and/or sustainability). This new approach should incorporate a holistic view of the production process in the manufacturing area. If it does not, then those actions end up focusing on the optimization of resources from a linear production management point of view. In this context, this paper uses real data and examples to compare a traditional improvement approach which is based on recirculating water for reducing its consumption, with an improvement approach based on the CE paradigm. The results of this study are intended to provide evidence for the need to deepen the way that companies measure the impacts of improvements to the production process. In this context, the two hypotheses presented in the previous section (introduction) are that the traditional strategies for making improvement in manufacturing do not allow manufacturers to obtain the real benefits of CE (H1), and the conventional metrics and tools do not facilitate productive and environmental efficiency to be simultaneously evaluated in a CE context $(\mathrm{H} 2)$.

\section{Materials and Methods}

This research study used the case study methodology. In general, case studies are the preferred method when "how" or "why" questions are being posed, or a lesser extent when "what" questions are being posed, which boosts the use of the case study. This method "allows investigators to retain the holistic characteristics of organizational and managerial process", as was needed here [40]. The case study methodology enabled us to respond to the need for deep understanding and local contextualization [41].

The objective of presenting these case studies is to be able to show in two real situations how the independent management of a resource may not be the most circular solution. On the one hand, these case studies clearly show the need to define adequate metrics for the management of these resources as part of the productive system. On the other hand, these case studies note the necessity of defining a holistic production strategy, where greater consumption of a resource in the production process does not necessarily imply a greater overall consumption of that resource in the factory. 
These case studies were carried out within the framework of the LIFE MCUBO European project (LIFE15 ENV/ES/000379), which focuses on reducing water and energy consumption in the agri-food sector in northern Spain.

During the past 50 years, the agri-food sector has become more resource-intensive and now represents a critical sector in Europe. Therefore, the EC is a relevant player in supporting agri-food companies in their efforts to conduct their business responsibly [42]. In Spain, the agri-food sector accounts for $11 \%$ of the GDP and in Europe the sector provides work to 44 million people [43].

The LIFE MCUBO project carried out 37 data collection campaigns in 21 companies, which means that almost 4 million data were recorded over three years of study. Each campaign used telemetry to collect data about the water consumed by different processes, which has made it possible to know not only how much water is spent, but also how this consumption is distributed over time.

The cases chosen in this paper are two of the most common processes in the sector: one is the blanching of vegetables and the other is the sterilization process used in an autoclave in a tuna canning company.

\section{Results}

This section analyzes the impact that a water recirculation process would have on two agri-food companies. This impact is studied from the two approaches described in the paper: a traditional approach from a LE perspective and a holistic approach which considers impacts according to the CE framework.

For the reuse of water in the process, there are numerous alternatives, such as membrane filtration, ozonation, chlorination or filtration using activated carbon, among others. These are technologies that allow process to operate in a closed loop way, considerably minimizing global water needs. In contrast, water from the water treatment plant can only be reused if national regulations for wastewater reuse practices are complied with (Royal Decree 1620/2007 in the case of Spain). In these cases, RD 1620/2007, for example, limits industrial use to process water, clean for use in the food industry, use in cooling towers and evaporative condensers. Although water has been an easy to obtain and cheap resource up until now, water is starting to become a scarce and high-value raw material, making the reuse of water essential.

These two cases will demonstrate how water flow can vary depending on the approach, leading to different justifications that support or reject the investment.

\subsection{Cooling Process after Blanching}

The water consumption curve during production setup processes (filling tanks, cleaning equipment to manufacture another product, etc.) can be easily known. The water meters installed in the company provide information for the total consumption recorded in a period of time. Rarely is this consumption shown as telemetry. However, real-time behavioral information could be very useful.

Knowing the consumption of the setup processes and how they flow over time helps to assess the total flow required. In this way, it will be possible to reduce it, compare it between products and, in what is most important in a continuous improvement environment, impute it to each product to see its impact on water consumption.

When cooling after scalding, the aim of the process is to reduce the temperature of the product quickly to keep bacteria from appearing and, at the same time, control the water flow to avoid water wastage. The following graph shows the telemetry of a blanching cycle. As can be seen in the graph, a much higher volume of water was used in the filling process (from 4:20 to 4:50 a.m.) compared to in the maintenance process (from 4:50 a.m.). After 4:50, water was continuously added to maintain the water level during blanching (Figure 2). 

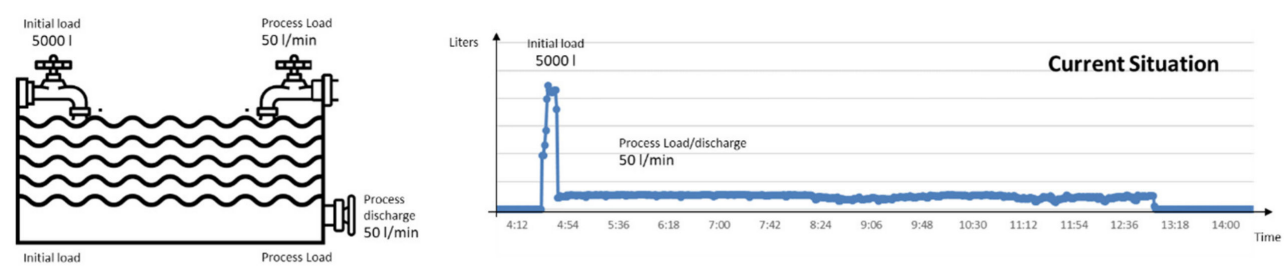

(a) Current situation.

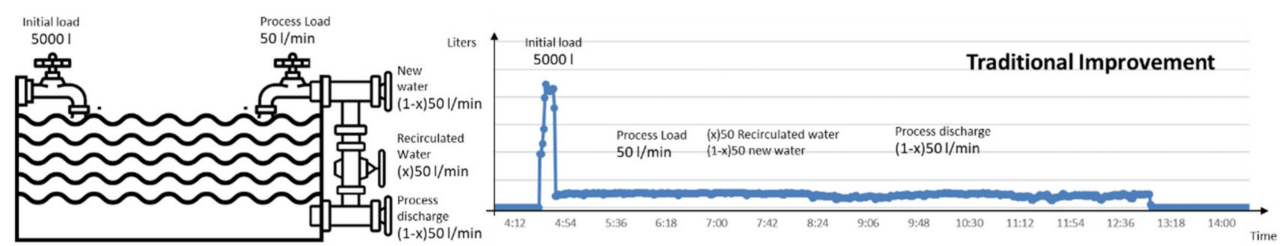

(b) Traditional strategy.

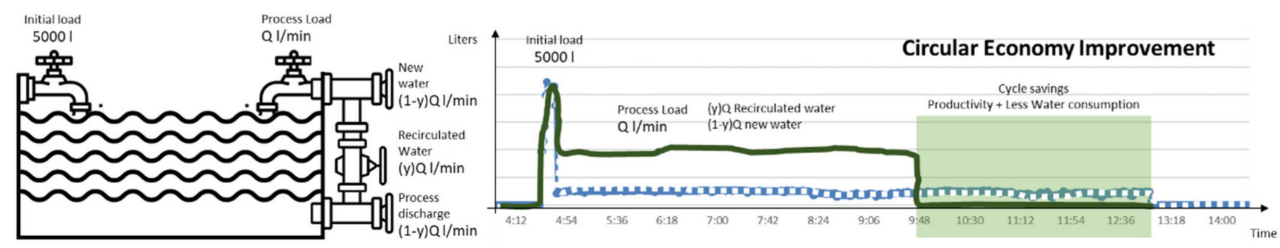

(c) Circular Economy strategy.

Figure 2. Telemetry of a cooling cycle.

\subsubsection{Current Situation}

Currently (Figure 2, top graph), the process has optimized water consumption under a linear economy, with its consumption during cooling being around $50 \mathrm{~L} / \mathrm{min}$, which is emptied into the sinkhole (discharged).

The company's managers assume that this process is optimized. Increasing the water flow could reduce the cooling time, but that would increase water consumption. Although the price of water is not high in Spain, environmental awareness prevents them from taking this action. Therefore, with the current parameters, a balance between productivity and sustainability is achieved.

\subsubsection{Traditional or Linear Strategy}

A traditional continuous improvement system would base its decisions on the current situation, assuming as a starting point the time and flow values in order to further reduce water consumption or reduce the production cycle.

From a traditional improvement strategy (Figure 2, middle graph), a water recirculation system would allow those 50 liters to recirculate into the process, eliminating the need for "new water". However, due to the organic matter load present in the water at the outtake concentration effect due to reuse, the percentage of the volume that could be recirculated $(x)$ would be very small and the need for "new water" will increase by $(1-x)$.

\subsubsection{Circular Economy Strategy}

A holistic improvement system would distinguish the flow of water used by the process and the actual water consumed, i.e., the use of "new water" that is incorporated. As a consequence, the current value of water consumption is not a fixed value but rather becomes a variable to be studied. The concept of resource reuse that was included in the Circular Economy proposal led the company to analyze a broader number of alternatives. 
As a result, from a CE perspective (Figure 3, bottom graph), a change in production strategy would not consider the optimized value of $50 \mathrm{~L} / \mathrm{min}$ as a fixed value. A volume of $\mathrm{Q} \mathrm{L} / \mathrm{min}$ would allow the volume to be recirculated $(\mathrm{y})$ to be increased while maintaining the appropriate organic load levels. Therefore, the flow of "new water" would be significantly reduced (1-y). In addition, a greater flow of water would reduce the cooling cycle (better productivity and less water consumption) but if the process is analyzed in isolation, the water consumption rate will be worse.

Unfortunately, at this moment there are no metrics that allow the best working conditions to be defined and measured in terms of productivity and circularity.

\subsection{Autoclave Process}

Water facilities in companies have a significant number of machines that are not usually monitored and, if they are, the consumption curve is not recorded in real time. But most production equipment that consumes water has control systems that start and stop processes, control parameters and show consumption values. However, in a few cases the values are recorded over time and the consumption or operating curves are unknown. In order to be able to improve the process, having knowledge of a specific value is not the same as knowing the behavior of a variable in real time, that is necessary to know. In this context, it is important to know the operation and water consumption of the equipment in real time in order to assess the total flow of water required, reduce it, compare it between products and split it to each product to see the impact on water consumption.

Figure 3 shows the telemetry for two autoclave cycles. The first peak represents the filling, followed by a longer cooling process. During cooling, the first part of the water supply is added gradually in order to avoid thermal shock. The final part involves a continuous supply of water until the temperature is reduced enough so the bags, cans, jars, etc. can be handled.
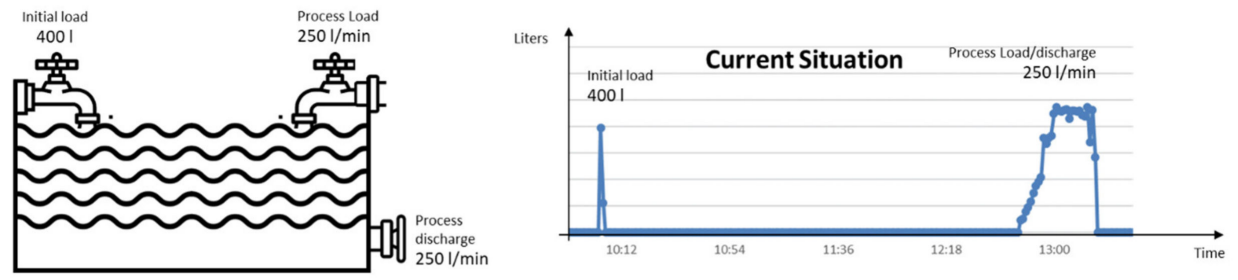

(a) Current situation.

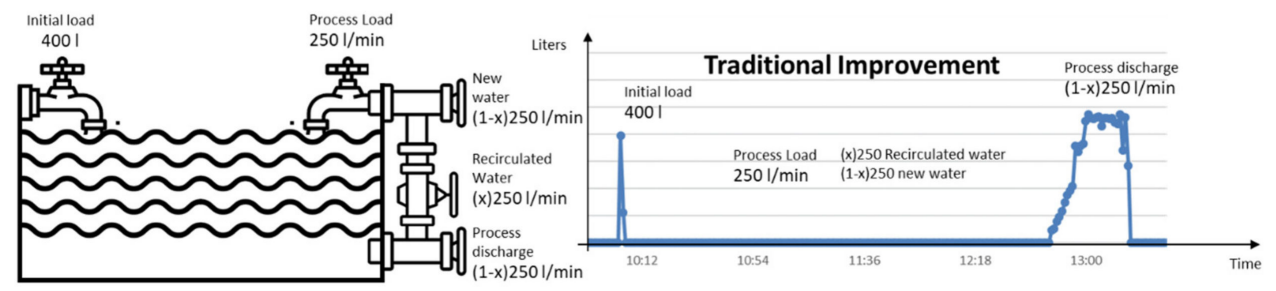

(b) Traditional strategy.

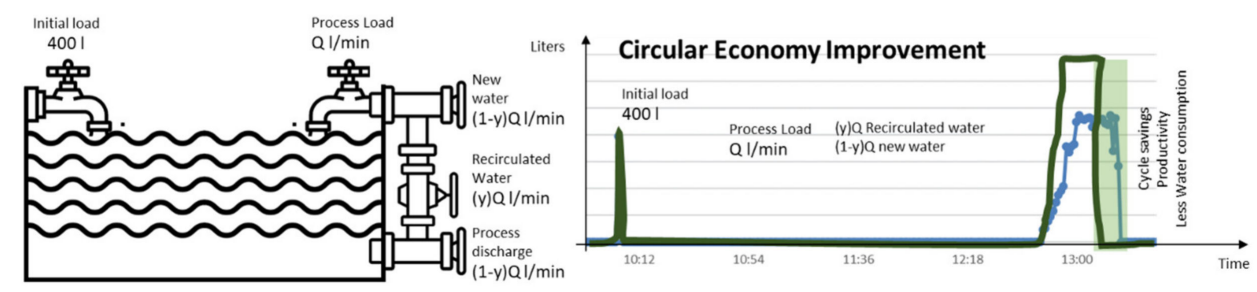

(c) Circular Economy strategy.

Figure 3. Telemetry for two autoclave cycles. 


\subsubsection{Current Situation}

In the current situation (Figure 3, top graph), the company, which does not know the real water consumption curve and only has data on consumption per autoclave cycle, has set the parameters of cooling time and water flow based on experience. This means that the automaton that provides water during the cooling process has been programmed based on the autoclave's internal temperature.

\subsubsection{Traditional or Linear Strategy}

The company is considering investing in water cooling systems that would further reduce water consumption, especially in the final part of the cycle. However, they reject investing in recirculation systems because the volume of water is not sufficient to justify the investment (see the middle graph in Figure 3).

In this case, it must be taken into account that the recirculation system should cool the water to the same temperature as the water supplied from the network, which increases equipment and operating costs. Again, a traditional continuous improvement system would base its decisions on the current situation, assuming as a starting point the time and flow values in order to further reduce water consumption or reduce the production cycle.

\subsubsection{Circular Economy Strategy}

A circular approach (Figure 3, bottom graph), which is aimed at reducing the net water consumption of the process, could justify the investment in the recirculation system, thus achieving more gradual cooling by having a higher flow of water at a higher temperature to avoid thermal shock. However, as explained above, it would be necessary to have a measurement tool that would make it possible to calculate the impact on the cycle time, net water consumption and quality of the final product.

\section{Discussion and Final Conclusions}

Currently, economic and environmental sustainability in industries is based on a circular economy, both in the use of raw materials and production processes and in the management and treatment of the waste generated.

The traditional approach to the planning and measurement of production systems can be changed to a circular approach by incorporating into the value streams the possibility of re-valuing or recirculating the waste generated. One of the current barriers to truly integrating the circular economy into processes is the lack of standardized indicators (or measures), methodologies and tools that allow the joint diagnosis of the production line and the treatment of the resource waste produced.

The two case studies presented in this paper have shown that the traditional approach of reducing the use of resources or proposing improvements supported by current process consumption cannot provide the best results with regard to sustainability; instead, the best results emerge only when the circularity of resources is considered. This idea supports the (H1) presented in the study.

Therefore, a holistic vision of the whole process is needed. Some authors have extended this holistic vision to the entire supply chain when implementing the CE [16,17]. In this context, Industry 4.0 technologies played a key role, since they enable the management and control of a system by taking a holistic view in order to manage the whole operation [44]. In particular for the wastewater treatment sector, in order to accelerate the transition to circular economy, the use treatment technologies such as a trickling filter, activated sludge, extended aeration and oxidation ditch constitute a major factor in determining the production efficiency [37].

Additionally, as this paper suggests, a new way of thinking is necessary when implementing CE strategies. In line with this, Blomsma et al. [45] proposed a new framework in which rethinking and reconfiguring actual business models are needed in order to implement CE strategies in the manufacturing sector. 
Furthermore, this new mindset implies that by using traditional metrics, the effect of a real improvement can be considered a loss of quality or productivity. In this context, profit maximization and cost minimization are no longer the only objectives of management [44].

Therefore, the concept of productivity and quality in manufacturing processes should be reformulated. The incorporation of circularity metrics should not only include a new set of indicators in the organizations, but also reflect a rethinking of the existing metrics by integrating the concepts of circular economy in the calculation of traditional indicators. Since the two real case studies confirms the hypothesis ( $\mathrm{H} 2)$ that the conventional metrics do not allow productive and environmental efficiency to be simultaneously evaluated in a circular context.

Having tools to measure the simultaneous capacity of a process to be circular and efficient will provide objective knowledge to managers, which will in turn help them to address within a global and orderly transition towards the Circular Economy their organization. Consequently, we believe that the definition of the new indicators may have a positive impact on all three aspects of the CE-economic, environmental and social-because the processing of new waste resources may lead to new professional profiles appearing in the field of manufacturing.

In a nutshell, for the past 100 years, companies have been involved in developing strategies to reduce the use of resources at the nano level, and the circular economy paradigm has been fit in this scenario. The two case studies described in this paper provide evidence for the fact that current company strategies aimed at reducing resource consumption do not consider the effects that would come from increasing the use of resources in a process linked to a reduction in the net water consumption of the resource due to its recirculation.

Author Contributions: Conceptualization, E.V., J.S. and T.F.A.; methodology, E.V., J.S. and T.F.A.; validation, E.V. and J.S.; formal analysis, E.V., J.S. and T.F.A.; investigation, E.V. and J.S.; resources, V.E., J.S.; data curation, T.F.A.; writing-original draft preparation, E.V. and J.S.; writing—review and editing, V.E., J.S., T.F.A., M.T. and F.K. All authors have read and agreed to the published version of the manuscript.

Funding: The work presented in this paper was carried out within the framework of the LIFE MCUBO (LIFE15 ENV/ES/000379) research project funded by the European Union, through the LIFE program.

Conflicts of Interest: The authors declare no conflict of interest.

\section{References}

1. Figge, F.; Thorpe, A.S.; Givry, P.; Canning, L.; Franklin-Johnson, E. Longevity and circularity as indicators of eco-efficient resource use in the circular economy. Ecol. Econ. 2018, 150, 297-306. [CrossRef]

2. Gregorio, V.F.; Pié, L.; Terceño, A. A systematic literature review of bio, green and circular economy trends in publications in the field of economics and business management. Sustainability 2018, 10, 4232. [CrossRef]

3. Kirchherr, J.; Reike, D.; Hekkert, M. Conceptualizing the circular economy: An analysis of 114 definitions. Resour. Conserv. Recycl. 2017, 127, 221-232. [CrossRef]

4. Prieto-Sandoval, V.; Jaca, C.; Ormazabal, M. Towards a consensus on the circular economy. J. Clean. Prod. 2018, 179, 605-615. [CrossRef]

5. Saidani, M.; Yannou, B.; Leroy, Y.; Cluzel, F. How to assess product performance in the circular economy? Proposed requirements for the design of a circularity measurement framework. Recycling 2017, 2, 6. [CrossRef]

6. Jaca, C.; Ormazabal, M.; Santos, J.; Viles, E. Circular Economy. Guide for SMEs; Ediciones; EUNSA: Pamplona, Spain, 2019; ISBN 978-84-313-3383-6.

7. Ellen Macarthur Foundation. Available online: https://www.ellenmacarthurfoundation.org/es/economiacircular/principios (accessed on 10 February 2020).

8. Bocken, N.M.P.; de Pauw, I.; Bakker, C.; van der Grinten, B. Product design and business model strategies for a circular economy. J. Ind. Prod. Eng. 2016, 33. [CrossRef]

9. Kalmykova, Y.; Sadagopan, M.; Rosado, L. Circular economy-From review of theories and practices to development of implementation tools. Resour. Conserv. Recycl. 2018, 135. [CrossRef] 
10. Prieto-Sandoval, V.; Jaca, C.; Santos, J.; Baumgartner, R.J.; Ormazabal, M. Key strategies, resources, and capabilities for implementing circular economy in industrial small and medium enterprises. Corp. Soc. Responsib. Environ. Manag. 2019, 26. [CrossRef]

11. Masi, D.; Kumar, V.; Garza-Reyes, J.A.; Godsell, J. Towards a more circular economy: Exploring the awareness, practices, and barriers from a focal firm perspective. Prod. Plan. Control 2018, 29. [CrossRef]

12. Garza-Reyes, J.A.; Salomé Valls, A.; Peter Nadeem, S.; Anosike, A.; Kumar, V. A circularity measurement toolkit for manufacturing SMEs. Int. J. Prod. Res. 2019, 57. [CrossRef]

13. Govindan, K.; Hasanagic, M. A systematic review on drivers, barriers, and practices towards circular economy: A supply chain perspective. Int. J. Prod. Res. 2018, 56. [CrossRef]

14. Acerbi, F.; Taisch, M. A literature review on circular economy adoption in the manufacturing sector. J. Clean. Prod. 2020, 273. [CrossRef]

15. Abu-Ghunmi, D.; Abu-Ghunmi, L.; Kayal, B.; Bino, A. Circular economy and the opportunity cost of not "closing the loop" of water industry: The case of Jordan. J. Clean. Prod. 2016, 131, 228-236. [CrossRef]

16. Schöggl, J.P.; Stumpf, L.; Baumgartner, R.J. The narrative of sustainability and circular economy-A longitudinal review of two decades of research. Resour. Conserv. Recycl. 2020, 163, 105073. [CrossRef]

17. Barreiro-Gen, M.; Lozano, R. How circular is the circular economy? Analysing the implementation of circular economy in organisations. Bus. Strateg. Environ. 2020. [CrossRef]

18. Sánchez-Ortiz, J.; Rodríguez-Cornejo, V.; Del Río-Sánchez, R.; García-Valderrama, T. Indicators to measure efficiency in circular economies. Sustainability 2020, 12, 4483. [CrossRef]

19. Rincón-Moreno, J.; Ormazábal, M.; Álvarez, M.J.; Jaca, C. Advancing circular economy performance indicators and their application in Spanish companies. J. Clean. Prod. 2021, 279. [CrossRef]

20. Saidani, M.; Yannou, B.; Leroy, Y.; Cluzel, F.; Kendall, A.; Saidani, M.; Yannou, B.; Leroy, Y.; Cluzel, F.; Kendall, A. A taxonomy of circular economy indicators. J. Clean. Prod. 2019, 207, 542-559. [CrossRef]

21. Moraga, G.; Huysveld, S.; Mathieux, F.; Blengini, G.A.; Alaerts, L.; Van Acker, K.; de Meester, S.; Dewulf, J. Circular economy indicators: What do they measure? Resour. Conserv. Recycl. 2019, 146, 452-461. [CrossRef]

22. Baraniecka, A. Ecologistics as a response of enterprises to the environmental crisis. Mark. Rynek 2019, 3-14. [CrossRef]

23. Kristoffersen, E.; Blomsma, F.; Mikalef, P.; Li, J. The smart circular economy: A digital-enabled circular strategies framework for manufacturing companies. J. Bus. Res. 2020, 120, 241-261. [CrossRef]

24. Sartal, A.; Ozcelik, N.; Rodríguez, M. Bringing the circular economy closer to small and medium entreprises: Improving water circularity without damaging plant productivity. J. Clean. Prod. 2020, 256, 120363. [CrossRef]

25. Skouteris, G.; Ouki, S.; Foo, D.; Saroj, D.; Altini, M.; Melidis, P.; Cowley, B.; Ells, G.; Palmer, S.; O’'Dell, S. Water footprint and water pinch analysis techniques for sustainable water management in the brick-manufacturing industry. J. Clean. Prod. 2018, 172, 786-794. [CrossRef]

26. Kurdve, M.; Bellgran, M. Green lean operationalisation of the circular economy concept on production shop floor level. J. Clean. Prod. 2020, 123223. [CrossRef]

27. Schuetze, T.; Santiago-Fandiño, V. Quantitative assesment of water use efficiency in urban and domestic buildings. Water 2013, 5, 1172-1193. [CrossRef]

28. Fu, X.; Guo, M.; Zhanwen, N. Applying the green Embedded lean production model in developing countries: A case study of china. Environ. Dev. 2017, 24, 22-35. [CrossRef]

29. Cherrafi, A.; Elfezazi, S.; Garza-Reyes, J.A.; Benhida, K.; Mokhlis, A. Barriers in green lean implementation: A combined systematic literature review and interpretive structural modelling approach. Prod. Plan. Control 2017, 28, 829-842. [CrossRef]

30. Morseletto, P. Targets for a circular economy. Resour. Conserv. Recycl. 2020, 153, 104553. [CrossRef]

31. Bressanelli, G.; Saccani, N.; Perona, M.; Baccanelli, I. Towards circular economy in the household appliance industry: An overview of cases. Resources 2020, 9, 128. [CrossRef]

32. Su, B.; Heshmati, A.; Geng, Y.; Yu, X. A review of the circular economy in China: Moving from rhetoric to implementation. J. Clean. Prod. 2013, 42, 215-227. [CrossRef]

33. Yang, C.L.; Lin, S.P.; Chan, Y.H.; Sheu, C. Mediated effect of environmental management on manufacturing competitiveness: An empirical study. Int. J. Prod. Econ. 2010, 123. [CrossRef] 
34. Habidin, N.F.; Hibadullah, S.N.; Mohd Fuzi, N.; Salleh, M.I.; Md Latip, N.A. Lean manufacturing practices, ISO 14001, and environmental performance in Malaysian automotive suppliers. Int. J. Manag. Sci. Eng. Manag. 2018, 13. [CrossRef]

35. Molina-Sánchez, E.; Leyva-Díaz, J.C.; Cortés-García, F.J.; Molina-Moreno, V. Proposal of sustainability indicators for the waste management from the paper industry within the circular economy model. Water 2018, 10, 1014. [CrossRef]

36. Molina-Moreno, V.; Leyva-Díaz, J.C.; Llorens-Montes, F.J.; Cortés-García, F.J. Design of indicators of circular economy as instruments for the evaluation of sustainability and efficiency in wastewater from pig farming industry. Water 2017, 9, 653. [CrossRef]

37. Kayal, B.; Abu-Ghunmi, D.; Abu-Ghunmi, L.; Archenti, A.; Nicolescu, M.; Larkin, C.; Corbet, S. An economic index for measuring firm's circularity: The case of water industry. J. Behav. Exp. Financ. 2019, 21, 123-129. [CrossRef]

38. Jefferies, D.; Muñoz, I.; Hodges, J.; King, V.J.; Aldaya, M.; Ercin, A.E.; Milà I Canals, L.; Hoekstra, A.Y. Water footprint and life cycle assessment as approaches to assess potential impacts of products on water consumption. Key learning points from pilot studies on tea and margarine. J. Clean. Prod. 2012, 33, 155-166. [CrossRef]

39. Muñoz-Villamizar, A.; Santos, J.; Viles, E.; Ormazábal, M. Manufacturing and environmental practices in the Spanish context. J. Clean. Prod. 2018, 178. [CrossRef]

40. Yin, R.K. Case Study Research: Design and Methods, 4th ed.; SAGE: Thousand Oaks, CA, USA, $2009 ;$ p. 4. ISBN 978-1-4129-6099-1.

41. Miles, M.B.; Huberman, A.M. Qualitative Qualitative Data Analysis: An Expanded Sourcebook; SAGE: Thousand Oaks, CA, USA, 1994.

42. Muscio, A.; Sisto, R. Are agri-food systems really switching to a circular economy model? Implications for European research and innovation policy. Sustainability 2020, 12, 5554. [CrossRef]

43. Eit Food. The Circular Economy in the Agrifood Sector is an Opportunity to Become More Resource-Efficient | EIT Food. Available online: https://www.eitfood.eu/news/post/the-circular-economy-in-the-agrifood-sectoris-an-opportunity-to-become-more-resource-efficient (accessed on 21 September 2020).

44. Ozkan-Ozen, Y.D.; Kazancoglu, Y.; Kumar Mangla, S. Synchronized barriers for circular supply chains in Industry 3.5/Industry 4.0 transition for sustainable resource management. Resour. Conserv. Recycl. 2020, 161, 104986. [CrossRef]

45. Blomsma, F.; Pieroni, M.; Kravchenko, M.; Pigosso, D.C.A.; Hildenbrand, J.; Kristinsdottir, A.R.; Kristoffersen, E.; Shabazi, S.; Nielsen, K.D.; Jönbrink, A.K.; et al. Developing a circular strategies framework for manufacturing companies to support circular economy-oriented innovation. J. Clean. Prod. 2019, 241. [CrossRef]

Publisher's Note: MDPI stays neutral with regard to jurisdictional claims in published maps and institutional affiliations.

(C) 2020 by the authors. Licensee MDPI, Basel, Switzerland. This article is an open access article distributed under the terms and conditions of the Creative Commons Attribution (CC BY) license (http://creativecommons.org/licenses/by/4.0/). 